\title{
Considerații teologice și estetico-muzicale asupra Recviemului în creația românească
}

\author{
Stelian IONAȘCU*
}

\begin{abstract}
Theological and aesthetic-musical considerations on the Requirem in the Romanian creation. Inspired by the brilliant musicological work of the composer and professor Adrian Pop - The Romanian Requiem -, in this paper the author makes an theologicalmusical analysis on this vocal-symphonic genre in the Romanian creation. More precisely, the author is focusing on the Parastasis Requiem (Recviemul parastas), composed by Marțian Negrea (+ 1973) and on a recent masterpiece of the genre, Commemoration - $A$ Parastasis Requirem (Pomenire-Un recviem parastas) by Ștefan Niculescu (+ 2008). The purpose of the study is to see how this synthesis between two different cultures - Western and Eastern - was achieved, both representing the psychological springs of a composition referring to the theme of the "great passage" and to highlight the theological, liturgical and musical means of
\end{abstract} expressing it at its finest.

Keywords: oratory, church music, parastasis, orchestra, syntax, a capella.

\section{Sintagma ,recviem românesc”}

Recviemul (lat. requiem aeternam = „odihnească-se în veci”) este prin excelență slujba de înmormântare după ritualul catolic, sinonim cu ,missa pro defunctis”, ,missa defunctorum”, ,missa pro fidelibus defunctis”, „missa pro mortis” ș.a. ${ }^{1}$ Această denumire a

* Preot, Conf. univ. la Facultatea de Teologie Ortodoxă „Justinian Patriarhul” a Universității București.

1 Dumitru Bughici, Dicționar de forme și genuri muzicale, București, Editura muzicală, 1976, p. 272; ***Dicționar de termeni muzicali, București, Editura 
fost preluată în componistica românească de gen, prin fuziunea între cele două culturi, orientală și occidentală. Fenomenul componistic în sine, pentru un recviem ,românesc" este complex și riscant. Compozitorii care și-au propus acest demers şi au publicat, sau măcar au validat în forma de manuscris o asemenea lucrare, șiau asumat toate consecinţele. De aceea nu sunt nici mulți compozitori români care să scrie un recviem (niciodată două), așa cum observăm că este un demers artistic singular și în creaţia universală${ }^{2}$. Pentru creația românească există riscul unei abordări epigonice sau cel puțin redundante și repetitive după niște tipare anterioare din muzica occidentală. Așa s-au născut ,recvieme românești”, care sunt românești prin autori, prin stilul componistic original, dar care respectă structura clasică a genului: orchestra, soli, cor și textul limba română $\breve{3}^{3}$. S-au scris apoi recvieme românești pe care Adrian Pop le numește ,parastase,"4 deoarece acestea folosesc melodii și ritualuri ortodoxe, textul în limba română, toate elementele fiind topite într-o sintaxă vocal-simfonică specifică muzicilor occidentale. De la pericolul redundanței unui recviem alcătuit după principiul clasic se poate ajunge la acuzația de ,prea multă îndrăzneală" sau de aliaje insuficient reușite între o tradiție autohtonă monodică milenară și aparatul orchestral specific unor

științifică și enciclopedică, 1984, p. 409; Adrian PoP, Recviemul Românesc, Cluj-Napoca, Edit. MediaMusica, 2004, p. 15.

${ }^{2}$ Cele mai cunoscute creații în literatura muzicală universală a acestui gen aparțin lui Mozar, Berlioz, Verdi și Faure. Inițial, recviemul era o missă gregoriană funebră, a capella, dar din sec. al XVII-lea se va transforma într-o compoziție cu acompaniament orchestral. În general, păstrează părțile cunoscute și textul religios în limba latină, dar recviemul devine un gen independent, cu un caracter grandios și tragic. Comparativ cu numărul impresionant de misse, unii compozitori celebri au scris doar câte un recviem, rareori două. Palestrina 103 misse, 1 recviem, Lassus - 53 misse, 1 recviem, Mozart - 18 misse, 1 recviem, Bruckner - 3 misse, 1 recviem, Cerubinni - 22 misse, 2 recvieme.

3 Au scris: Nicolae Betan (1887-1968), Șerban Nichifor (n. 1952) și Wilhelm Georg Berger (1929-1993).

4 Au scris: Zeno Vancea (1900-1997), Sabin V. Drăgoi (1894-1968), Marțian Negrea (1893-1975) și Marian Dinu (n.1945), A. PoP, Recviemul..., p. 68 și p. 148 ș.u. 
tipare împrumutate. Evident că toate temerile au fost risipite de însăşi actul creator unic şi de momentul revelator al recreării partiturii în concerte, precum și de o seamă de studii muzicologice care certifică genialitatea unora dintre creațiile de gen menite să se alinieze cu demnitate marilor capodopere universale.

Rămânem însă la fenomenul în sine al plămădirii recviemului românesc. Considerată de Adrian Pop o sintagmă cel puțin excesivă $\breve{5}^{5}$, (recte „recviem românesc”), m-am confruntat cu aceeaşi situație la analiza oratoriilor în compozitia românească, cu referire directă la creațiile lui Paul Constantinescu. Toate genurile religioase vocal-simfonice - oratoriu, cantată, recviem - deși fac parte din tradiția catolică, au fost asimilate, acceptate și aprobate în interiorul comunității românești ortodoxe, majoritare și conservatoare. Ar părea destul de neobișnuit, dacă ne gândim la faptul că Biserica ortodoxă ține cu tărie la păstrarea dogmelor, a tradiției muzicale și liturgice moștenite. Temerile sunt risipite dacă ne gândim la faptul că aceste noi creații vocal-simfonice nu intră în practica liturgică sacramentală, fie și la nivel de ierurgie, ci se limitează la prezentarea sau (re)prezentarea lucrărilor în concerte, săli de spectacole și nu în biserici. Satisfacția auditorului - fie ea și una de revelație sacră - este aceea a extensiei melodiilor din strana bisericii în marile săli de concerte, la care adăugăm bucuria recunoaşerii acestor cântari printre celelalte angrenaje sonore, prezentate într-o lumină nouă în regia compozitorului și interpreților.

\section{Preliminarii, anticipări, prefigurări și convergențe}

Inspirați de geniala lucrare muzicologică a compozitorului și profesorul Adrian Pop - Recviemul românesc - vom căuta să depășim macar temporal stadiul de cercetare la care a ajuns emeritul muzician, odată cu publicarea cărții în 2004. Cartea de 359 de pagini analizează fenomenologic și muzical creația de gen a

\footnotetext{
${ }^{5}$ A. PoP, Recviemul..., p. 6.
} 
recviemului românesc $\mathrm{cu}$ toate ramificațiile și conexiunile tangențiale ritualice și de liturgică comparată, cuprinzând o seamă de amănunte științific argumentate menite să confere exhaustivitate asupra acestei teme. Studiul nostru are în vedere o abordare mai mult teologico-muzicală și își lărgește atenția și după anul 2004, cuprinzând o ultimă capodoperă a unui recviem românesc, creaţia lui Ștefan Niculescu $(† 2008)$.

Preliminariile și anticipările unor creații de anvergură sunt reprezentate de o seamă de factori care au lansat școla românească de compoziție pe orbita recunoașterii internaționale. Tradiția monodică psaltică (bizantină), anterioară marilor primeniri și realizări în planul muzicii culte, a constituit seva din care aveau să se hrănească viitoarele compoziții românești de inspirație religioasă. Pr. I D Petrescu propunea lui Paul Constantinescu alcătuirea unor oratorii pornind de la niște simple monodii biantine, transcrise și diortosite de acesta după manuscrise vechi. Marțian Negrea și Sabin Drăgoi folosesc melodiile de strană din Transilvania şi Banat pentru a turna într-un creuzet alt gen muzical, recviemul.

Așadar, preliminariile și anticipările sunt marcate în special de pătrunderea cântării corale la români, odată cu începutul de secol XIX: Corul arhimandritului Visarion la București (1836), corul călugărilor de la Mănăstirea Neamț în vremea stăreției Sf. Paisie Velicicovschi (cor de limbă slavonă cu o longevivă activitate între 1792-1850), corul învătătorului Ghina (1840) în Banat, corul din Sibiu în vremea mitropolitului Andrei Şaguna (1850) şi mai ales atenția domnitorului Alexandru Ioan Cuza pentru corurile de la peste 15 biserici din București, cu coriști plătiți de guvern, au stat la baza răspândirii muzicii corale în țara noastră ${ }^{6}$. Se poate observa că ușa Bisericii ortodoxe, implicit prin contribuția mănăstirilor, s-a deschis unei „noutăți” care a și scandalizat inițial pe câțiva ierarhi. Nu le-a fost uşor să audă la Sfânta Liturghie o muzică construită pe raporturi funcționale altele decât vechea monodie melismatică

${ }^{6}$ Stelian IONAȘCU, Cultura corală bisericească la români. Documente din Arhiva Mitropoliei Ungrovlahiei (1876-1897), București, Edit. Basilica, 2019, 559 p. 
însoțită de ison. Și, cu toate acestea, așa cum ierarhia din secolul al XIX-lea a acceptat cântarea în cafas ca pe o exprimare emfatică a Liturghiei în Duminici și sărbători, mai târziu, în 1946, Patriarhul Nicodim avea să asiste la Ateneu, la premiera oratoriului Patimile Domnului de Paul Constantinescu sub bagheta lui George Enescu și să trimită o scrisoare de apreciere și mulţumire dirijorului, compozitorului și pr. I. D. Petrescu?

În felul acesta, Biserica a făcut primul pas pentru nașterea și promovarea cântului coral în țara noastră. Interzicerea dintotdeauna a instrumentelor în cultul ortodox a avut ca urmare preluarea ștafetei de către școlile de stat de profil, școli filarmonice, conservatoare, teatre muzicale, iar dezvoltarea fenomenului muzical vocal-simfonic cu tematică religioasă să rămână în grija compozitorilor. Propriu-zis, Biserica nu mai poate continua dincolo de platoul creațiilor liturgice corale a capella. Încurajează orice creație cultă care promovează melodiile tradiționale de strană, dar rămâne categorică interzicerii instrumentelor muzicale în cadrul liturgic ${ }^{8}$.

Cele mai vechi lucrări cu specific de parastas la români sunt: Reqviem de György Ruzicka (1819?) și Requiem, cor, soli, orchestră de Friedrich Daniel Speer (1877) ${ }^{9}$. Fără a se sti prea multe despre partiturile respective, acestea rămân cu titlu informativ, ca simple anticipări, fiind prematură o apariție genială în sec. al XIX-lea, pentru lucrări vocal-simfonice de anvergură. Germenii însă aici au început să încolțească, ceea ce dovedeste încă odată că individualul se detaşează ca etalon, țâşnind din sfera generalului şi întotdeauna creațiile valoaroase nu pot face abstracție de experiența înaintașilor.

Pînă la construirea unor edificii dezvoltate ca formă şi dimensiune, așa cum se prezintă recviemul, asistăm la apariția unor

${ }^{7}$ Detalii în: Vasile Tomescu, „Patimile și Învierea Domnului. Oratoriu bizantin de Paști de Paul Constantinescu", în Muzica, 1/1990, p. 58-59; Stelian IonAșCU, Oratoriile lui Paul Constantinescu, București, Edit. Universității din București, 2018, pp. 64-65.

8 A se vedea păreri pro și contra în: Stelian IonAȘCU, „Gheorghe Șoima. Funcțiunile muzicii liturgice - o viziune îndrăzneață”, în Preotul compozitor Gheorghe Șoima (1911-1985). Simpozionul Național de Muzicologie, Sibiu, 4 dec. 2010, Sibiu, Edit. Universității „Lucian Blaga”, pp. 38-49.

${ }^{9}$ A. Pop, Recviemul..., p. 67. 
lucrări corale a capella cu tematică funerară ${ }^{10}$. Aceste lucrări nu pot fi considerate totdeauna anticipări temporale, multe fiind creații simultane și „,post” aparițiilor vocal-instrumentale ale recviemului românesc, dar sunt ramificații care anunță interesul pentru opere funerare complete. De multe ori, partiturile a capella din oratorii, cantate și recvieme, reintră în practica de cult, așa cum s-a întâmplat practic prin extragerea din partiturile generale vocalinstrumentale a unor piese corale cu care au performat diferite coruri, eliminând suportul instrumental, tocmai pentru a putea fi interpretate în biserici. Fenomenul se regăsește atât în cazul Oratoriilor lui Paul Constantinescu, cât și la Recviemul lui Marțian Negrea sau cantata Mântuire de Gheorghe Firca. Reîntoarcerea la „bază” a acestor melodii, care au trecut deja prin prefaceri complexe, are avantaje și dezavantaje. Credem că poate să aducă mulțuire sufletească autorului care aude ceva din lucrarea sa într-un cadru sacru, dar trebuie să se resemneze că opera nu poate fi reprodusă în integralitatea ei, iar numerele corale izolate sunt lipsite de suportul orchestral.

Tot la acest capitol al prefigurărilor și convergențelor trebuie să luăm în considerare anumite teme contigue care lansează această mare provocare a trecerii dincolo: ritualurile de proveniență precrestină sau păgână, bocetele și tema morții din balada Miorița. Enumerată de George Călinescu între cele patru miturile ancestrale ale românilor, balada Miorița a constituit prilej de inspirație atât pentru partituri corale a capella, dar și pentru lucrări vocal-simfonice ${ }^{11}$.

${ }^{10}$ Ciprian Porumbescu (1853-1883) - Adusu-mi-am aminte, În mormânt, Viață, Vecinica pomenire; Gheorghe Mandicevschi (1870-1907) - Cântec funebral; Dimitrie Cunțanu (1837-1910) - Cântări funebrale (cor bărbătesc); Gheorghe Dima (1847-1925) - Cântări funebrale, ciclul I și II (cor mixt); Ion Vidu (1863-1931) - Cântări funebrale (cor mixt); Antoniu Sequens (1865-1938) Cântări funebrale (cor mixt); Cornel Givulescu (1893-1969) - Cântări pentru morți (cor bărbătesc); Ioan D. Chirescu (1889-1980) - Adusu-mi-am amite (cor mixt) și Plâng și mă tânguiesc (cor mixt).

11 George CĂLINESCU, Istoria literaturii române de la origini până în prezent, București, Edit. Minerva, 1985, pp. 56-60. Cele mai cunoscute lucrări inspirate din balada Miorița aparțin compozitorilor prezentați în studiul următor: Carmen Stolanov, Miorița în creația a trei compozitori: Paul Constantinescu, 


\section{Impusul psihologic de a scrie un recviem}

Recviemul este o lucrare greu de scris mai ales din punct de vedere psihologic. Dacă este compusă în debutul artistic al unui autor nu are o justificare motivațională, dacă este compusă prea târziu ar putea fi considerată ca o lucrare de „bun rămas”. Am citit cu emoție o aducere aminte relatată de Adrian Iorgulescu în Ștefan Niculescu. Portret în eterofonie ${ }^{12}$ : ,...recviemul, o capodoperă pe care știam că n-a vrut să o finalizeze", recviemul a fost compus în virtutea unei „premoniții”, iar partitura este ca un „cântec de lebădă”, fiind ultima din creația lui Ștefan Niculescu. Este drept că în credința creștină ortodoxă, spaima viscerală în fața morții și perspectiva neantului insondabil sunt echilibrate de teologia Morții și Învierii lui Hristos, prelungirea indefinită a existenței dincolo de moarte sau, conform exprimării optimiste a Pr. Dumitru Stăniloae, expectativa unei „,veșnici existențe fericite"13.

Se știe despre Ștefan Niculescu faptul că a avut o stare continuă de rugăciune, 1-a avut duhovnic pe pr. Sofian Boghiu, iar prelegerile sale în calitate de profesor la Conservator, în vremea îngrădirilor comuniste, erau presărate de gânduri și texte religioase, îndemnând studenții să citească Filocalia.

„Complexitatea partiturilor niculesciene - încărcate de isoane, sincronii, eterofonii, structuri modale, procedee matematice - a fost supusă cel mai adesea expresiei religioase" ${ }^{\text {"14. Așa se }}$ explică faptul că muzica sa este impregnată de religiozitate ca și

Anatol Vieru, Sigismund Toduță, în Studii de muzicologie, Vol. X, București, Edit. Muzicală, 1974, pp. 111-125.

12 Adrian IORGulescu, „Stăpânul sunetelor”, în Olguța LuPU și Florinela POPA (eds.), Ștefan Niculescu. Portret in eterofonie, Muzeul Național „George Enescu", Editura muzicală, 2015, p. 20.

13 Dumitru Stănilone, Teologia Dogmatică Ortodoxă, vol. I, București, Edit. Institutului Biblic și de Misiune Ortodoxă al Bisericii Ortodoxe Române, 1996, p. 131 ș.u.

${ }^{14}$ Valentina SANDu-Dediu, „Câteva teme ale muzicii lui Ștefan Niculescu”, în O. Lupu și F. Popa (eds.), Ștefan Niculescu..., p. 31. 
viaţa lui. A exprimat sacrul în partiturile sale nu doar prin titlu, text sau tematică ci este vorba despre un sacru intrinsec al muzicii care, de cele mai multe ori, era o muzică instrumentală.

„Sacrul este ținta supremă a muzicii. Ea tinde către sacru chiar și când este profană sau când își uită destinul de a-1 sluji. Doar un titlu sau un text spiritual folosit în muzică nu o califică automat drept sacră, căci sacrul este în muzică un dar, o prezență ce depășește puterile creatoare ale omului. Există muzici religioase atât de îndoielnice ca substanță, încât profanează până și textele pe care au fost compuse"15.

La un concert de la Sala Radio (2007), când a avut loc și lansarea partiturii tipărite la Editura Academiei Române Pomenire. Un Recviem Românesc pentru bas solo, cor mixt și orchestră - împreună cu reluarea în concert a lucrării sub bagheta dirijorului Tiberiu Soare, am primit un scurt autograf pe partitura generală ${ }^{16}$. Îmi amintesc că am avut o remarcă stângace, spunând că partitura este tipărită după aceeași metodă ca oratoriile lui Paul Constaninescu și mi-a răspuns zâmbind că este o altă abordare stilistică. Atunci am realizat că Ștefan Niculescu, acest colos al muzicii moderne românești, „uneori socratic și ironic, alteori prietenos, mereu intransigent și totodată generos" $" 17$, este printre puținii muzicieni cu autoritate care să exprime cu demnitate şi alte păreri decât toată lumea. „În anii 1965-70 1-am auzit pe Ștefan Niculescu afirmând că el nu are nimic împotriva inspirației de origine balcanică în compoziție dar nu acceptă felul în care o vede Paul Constantinescu" ${ }^{18}$. Se referea la muzica ,aproape de mahala, o subcultură hibridă,

15 Ștefan Niculescu, Reflecții despre muzică, București, Edit. Academiei Române, 2006, p. 168.

16 „Părintelui Stelian Ionașcu, împreună cu bucuria spirituală de a întâlni aici un cleric al Bisericii noastre, și cu speranța că pe noi toți ne va pomeni Domnul Nostru Iisus Hristos când va veni întru împărătia Sa. Ștefan Niculescu, 25.05. 07’'.

${ }^{17}$ V. SAndu-Dediu, „Câteva teme...”, p. 31.

18 Corneliu Dan GEORGESCU, „Ștefan Niculescu și noțiunea de ethos muzical”, în O. Lupu și F. PopA (eds.), Ștefan Niculescu ..., p. 43. 
lipsită de orice tradiție"19. Sobrietatea lui Ștefan Niculescu trebuie înțeleasă în lumina sacrului și profanului în muzică. Paul Constantinescu este autorul a două Oratorii - de Paști și de Crăciun -, a unui Liturghii psaltice și a numeroase lucrări instrumentale de inspirație bizantină, dar a scris și muzică cu ton glumeț, picant și grotesc. Şi Bach a avut motive serioase să nu scrie niciodată operă, considerând că decorurile și mișcarea scenică ar diminua din consistența muzicii ${ }^{20}$, dar Ștefan Niculescu evită orice atingere de trivial în muzică din considerente spirituale. De aceea, însăși dedicația de la nota 16 exprimă ceva din sufletul profund și strâns legat de Dumnezeu al acestui mare compozitor român. În asemenea condiții, valoarea incontestabilă a Recviemului lui Ștefan Niculescu reprezintă mai mult decât o moștenire lăsată umanității: este o „carte de vizită” sau un „card” de acces în împărăția cerurilor.

Recviemul lui Marțian Negrea (1957), deși a rămas "la sertar" până în anul 1990, a reușit să între în programul diferitelor filarmonici și să stârnească interes ca subiect de cercetare muzicologică, fiind considerat de către Adrian Pop drept o lucrare "reprezentativă $\breve{21}^{1}$ " și "opera vieții" 22 de Veturia Dimoftache. Autorul acestei lucrări s-a stins din viaţă cu dezamagirea mărturisită că nu și-a ascultat recviemul în lumea acesta. A căutat să înșele vigilența regimului comunist dar fără rezultate. Deși iniţial recviemul a fost compus ca „omagiu eroilor neamului”, pe partitură apare „în memoria lui George Enescu,” cu speranța că va fi cântat în amintirea celui mai mare compozitor român. Din formularea titlului se revelează intenția autorului de a plasa un gen vocal-simfonic în sfera românească de inspirație bisericească, cu toate implicațiile de remodelare stilistică. Așadar, la motivații pentru scrierea acestui oratoriu, Marțian Negrea rămâne detașat

${ }^{19}$ C. D. GeORGESCU, „STtefan Niculescu...”, p. 43, n. 1.

${ }^{20}$ George BăLan, Misterul Bach, București, Edit. Florile Dalbe, 1997, p. 287.

${ }^{21}$ A. PoP, Recviemul..., p. 6.

22 Veturia Dimoftache, Marțian Negrea, Iași, Edit. Novum, 2003, p. 225. A scris despre Marțian Negrea și Vasile VAsile, „Recviemul-Parastas de Marțian Negrea", în Muzica, 3/1993, pp. 61-69. 
din punct de vedere emoțional și personal. Sabin Drăgoi (1943) a scris un Recviem românesc (Parastas), sub impresia profundă a morții soției sale, iar la raspusurile nr. 65, 66, 67, este o însemnare, ,în amintirea fiicei mele Florica, decedată la 13 noiembrie 1942". Marțian Negrea a scris partitura cu intermitențe, în aproape $20{\text { de } a n i^{23}}^{2}$ și a avut neșansa să treacă timpul peste ea încă 30 de ani până să fie interpretată postum. Ceea ce reușește Marțian Negrea cu Recviemul său este asemănător, dar într-un plan paralel, cu demersul lui Paul Constantinescu în cele două Oratorii: o fuziune între două culturi distincte, prin remodelarea tiparului clasic în funcție de detaliile specifice ale surselor muzicale românești. Am putea compara Recviemul lui Marțian Negrea cu o catedrală măreață din vestul Europei, reinterpretată și ridicată cu cărămizi autohtone și rezultând o Biserică voievodală, care adună în jurul său ambianța clădirilor unui oraș transilvănean.

Ștefan Niculescu a scris Recviemul în 2003, deși partitura generală din Biblioteca Universității de Muzică din București este fără an de apariție. În 2006 partitura este tipărită la Editura Academiei Române prin fotocopierea manuscrisului. Dacă în manuscrisul din 2003 Recviemul are 6 părți, în lucrarea tipărittă adaugă încă o parte, întregind astfel numărul $7 \mathrm{cu}$ semnificații simbolice evidente în tradiția iudeo-creștină. Mai mult, textul ales pentru această ultimă parte din Recviem este sugestiv. Întărește toate convingerile unei lucrări testament, iar autorul se prezintă în fața Dreptului Judecător ca în fața unei icoane celebre din tradiţia ortodoxă, Deisis, în care Maica Domnului devine mijlocitoare și părtinitoare cum doar o mamă poate fi, înaintea Judecătorului nemitarnic Hristos: „Născătoare de Dumnezeu mântuiește pe cei ce nădăjduiesc în tine și fă milostiv, cu rugăciunile tale, pe bunul Dumnezeu, să dea odihnă celui răposat, unde sufletelor drepților se odihnesc: arată-l moștenitor al bunurilor celor dumnezeiști, în locașurile drepților, întru veșnică pomenire ceea ce ești întru totul fără prihană..." (7. Pomenirea, pentru cor și orchestă). Compozitorul face uzanță de multe mijloace de exprimare, atât muzicale cât și de text prin selectarea cu mare atenție și

${ }^{23}$ V. Dimoftache, Marțian Negrea..., p. 230. 
rafinament teologic a unor momente din slujba înmormântării mirenilor. Titlul lucrării - Pomenire. Un Recviem Românesc - este unul potrivit. Nu urmează linia unui recviem clasic cu text în limba latină, nici nu are structura unui parastas ortodox, ci face o sinteză din quasi-respectarea paradigmei universale a genului și texte românești adecvate: 1. Odihnește, Mântuitorule (corespunde oarecum catolicului Requem aeternam)..., 2. Doamne miluiește (corespunde catolicului Kyrie eleison și Christe eleison)..., 5. Strigătul Atoţ̦iitorului (corespunde oarecum catolicului Dies irae) ${ }^{24}$. Deoarece ritualul trecerii este unul plin de superstiții și tradiții la români, Ştefan Niculescu recurge în partea a 3-a a Recviemului la un text din repertoriul lui Constantin Brăiloiu, Zorile, dintr-un studiu publicat în 1936, „Ale mortului de Gorj”, iar din considerente pe care doar le bănuim - o evlavie deosebită pentru Fecioara Maria - are o inervenție scurtă cu Sancta Maria ora pro nobis, temă dintr-o lucrare de Claudio Monteverdi. Așa cum am spus, în forma definitivă a partiturii, compozitorul aduce în partea a 7-a, cu textul românesc, o rugăciune către Maica Domnului de mijlocire în ceasul morții, Născătoare de Dumnezeu. Alege fragmente din Stihirile glasurilor la înmormântare (Care desfätare lumească, Vai, câtă nevoie are sufletul, Deșertăciuni sunt toate cele omenești) și Evanghelia de la Slujba înmormântării mirenilor, pe care basul solist o recită ecfonetic, din loc în loc cu interludii responsoriale la cor de bărbați pe textul „Doamne miluiește".

Lucrarea are o încărcătură emoțională deosebită, cu stări de teamă în tandem cu cele de speranță revelatoare, oferind nu doar simple trăiri artistice specifice concertelor și sălilor de concert, ci implicații estico-filosofice existențiale generate de întâlnirea omului ca ființă vremelnică cu Creatorul său în fața morții. O serie de analize muzicale ale acestei monumentale lucrări, trasează implacabil traiectoria componistică a compozitorului spre un platou artistic original și greu de atins de către școala românească de compoziție în viitorul apropiat. La o sumară decriptare a partiturii

${ }^{24}$ Ștefan Niculescu, Pomenire. Un Recviem Românesc. Partitură, București, Edit. Academiei Române, 2006, pp. 9-10. 
se poate observa că nu există o linie melodică adiţională, un cantus firmus pe care să le urmărească auditorul, asa cum întâlnim la Marțian Negrea și în general la lucrările care se folosesc de sintaxe omofone sau polifone. La Ștefan Niculescu linii melodice bazate pe oligocordii şerpuiesc sinuos împreună cu altele cu care se întrepătrund și iar se despart, generând fluxuri timbrale suprapuse care se sudează în blocuri sonore indestructibile. Muzica lui Ștefan Niculescu nu poate fi ascultată decât dacă este privită și contemplată dintr-o perspectivă panoramică.

\section{Concluzii}

Creațiile vocal-instrumentale de inspirație religioasă în componistica românească sunt apreciate ca lucrări originale şi izbutite atât în spaţiul autohton cât și pe plan internaţional. Cele trei genuri reprezentative - oratoriu, recviem, cantată - au oferit măsura competenței și maturității şcolii românești de compoziţie. Compozitorii români au înțeles că sursele oferite de monodia bizantină și de cântările de strană ale Bisericii noastre ortodoxe sunt un tezaur inestimabil, care merită să fie exploatat cu interes şi pricepere pentru a putea fi valorificat sub noi aspecte sintactice și morfologice, astfel încât sunetul finit să reveleze genuri și forme ingenioase şi reprezentative. Pe parcursul studiului am arătat că în ceea ce priveste recviemul românesc, compozitorii s-au grupat rațional pe anumite orbite stilistice. Unii au rămas la forma clasică a recviemului cu textul în limba latină, alții au optat pentru tiparul clasic, dar cu textul și cântările autohtone. Ştefan Niculescu se detașează de tot ceea ce s-a scris până acum prin modul original de construcție din toate punctele de vedere: numerele sale „corespund oarecum catolicului Requiem aeternam, Kyrie eleison sau Dies irae" , sintaxa eterofonă impune o rezonanță masivă de blocuri sonore sudate, alegerea textelor bisericești este la fel de originală, iar monodia bizantină este sugerată şi reinterpretată de traiectoria orizontală oligocordică a vocilor în straturi diversificate timbral. 


\section{Bibliografie}

1. BĂLAN, George, Misterul Bach, București, Edit. Florile Dalbe, 1997.

2. BughicI, Dumitru, Dicționar de forme și genuri muzicale, București, Editura muzicală, 1976.

3. CĂLINESCU, George, Istoria literaturii române de la origini până în prezent, București, Edit. Minerva, 1985.

4. ***Dicționar de termeni muzicali, București, Editura științifică și enciclopedică, 1984.

5. DimOFTACHE, Veturia, Marțian Negrea, Iași, Edit. Novum, 2003.

6. GEORGESCU, Corneliu Dan, „Ștefan Niculescu și noțiunea de ethos muzical", în Olguța LuPU și Florinela POPA (eds.), Ștefan Niculescu. Portret în eterofonie, Muzeul Național „George Enescu”, Editura muzicală, 2015, pp. 43-49.

7. IONAȘCU, Stelian „Gheorghe Șoima. Funcțiunile muzicii liturgice - o viziune îndrăzneață”, în Preotul compozitor Gheorghe Șoima (19111985). Simpozionul Naţional de Muzicologie, Sibiu, 4 dec. 2010, Sibiu, Edit. Universității „Lucian Blaga”, pp. 38-49.

8. IONAȘCU, Stelian, Oratoriile lui Paul Constantinescu, București, Edit. Universității din București, 2018.

9. IONAȘCU, Stelian, Cultura corală bisericească la români. Documente din Arhiva Mitropoliei Ungrovlahiei (1876-1897), București, Edit. Basilica, 2019.

10. IORGULESCU, Adrian, „Stăpânul sunetelor”, în Olguța LuPU și Florinela POPA (eds.), Stefan Niculescu. Portret in eterofonie, Muzeul Național „George Enescu”, Editura muzicală, 2015, pp. 20-23.

11. Niculescu, Ștefan, Pomenire. Un Recviem Românesc. Partitură, București, Edit. Academiei Române, 2006.

12. NiCULESCU, Ștefan, Reflecții despre muzică, București, Edit. Academiei Române, 2006.

13. PoP, Adrian, Recviemul Românesc, Cluj-Napoca, Edit. MediaMusica, 2004.

14. SANDU-DEDIU, Valentina „Câteva teme ale muzicii lui Ștefan Niculescu" în Olguța LuPU și Florinela POPA (eds.), Ștefan Niculescu. Portret în eterofonie, Muzeul Național „George Enescu”, Editura muzicală, 2015, pp. 31-42.

15. StăniloAe, Dumitru, Teologia Dogmatică Ortodoxă, vol. I, București, Edit. Institutului Biblic și de Misiune Ortodoxă al Bisericii Ortodoxe Române, 1996. 
16. Stolanov, Carmen, Miorița in creația a trei compozitori: Paul Constantinescu, Anatol Vieru, Sigismund Toduță, în Studii de muzicologie, vol. X, București, Edit. Muzicală, 1974.

17. TOMESCU, Vasile, „Patimile şi Învierea Domnului. Oratoriu bizantin de Paşti de Paul Constantinescu", în Muzica, 1/1990, pp. 58-69.

18. VASILE, Vasile, „Recviemul-Parastas de Marțian Negrea”, în Muzica, 3/1993, pp. 61-69. 